\title{
Effect of a Decellularized Omentum Scaffold With Combination of Mesenchymal Stem Cells and Platelet Rich Plasma on Healing of Critical-sized Bone Defect
}

Abdulsamet Emet ( $\nabla$ drsametemet@gmail.com )

Hacettepe Universitesi https://orcid.org/0000-0001-5415-218X

\section{Erdi Ozdemir}

Hacettepe University: Hacettepe Universitesi

\section{Duygu Uckan Cetinkaya}

Hacettepe University: Hacettepe Universitesi

Emine Kilic

Hacettepe University: Hacettepe Universitesi

\section{Ali Celalettin Sinan Yuruker}

Usak University: Usak Universitesi

\section{Ramin Hashemihesar}

Istanbul Aydin University: Istanbul Aydin Universitesi

\section{Egemen Turhan}

Hacettepe University: Hacettepe Universitesi

\section{Research Article}

Keywords: segmental bone defect, PRP, omentum, scaffold, mesenchymal stem cell

Posted Date: August 17th, 2021

DOI: https://doi.org/10.21203/rs.3.rs-806042/v1

License: (c) (i) This work is licensed under a Creative Commons Attribution 4.0 International License. Read Full License 


\section{Abstract}

Background: High-cost and the long time needed for the treatment of critical-sized bone defects is still major clinical concern in orthopedic surgery, therefore new research continues to identify more cost and time-effective methods. In this study, we aimed to investigate the effect of a decellularized omentum scaffold with a combination of platelet-rich plasma (PRP) and mesenchymal stem cells on the healing of critical- sized bone defects.

Materlials and methods: Wistar albino rats $(n=30)$ were investigated in five groups. Critical-sized bone defects were formed on bilateral radius shafts. To increase healing, no scaffold, decellularized omentum, omentum with with PRP and omentum mesenchymal stem cells was used in group 1 (control group) , 2, 3 and 4 respectively. In addition omentum with a combination of mesenchymal stem cells and PRP was used in group 5. After 6 weeks, both radiological and histological healing were evaluated comparatively among groups.

Results: After use of decellularized omentum scaffold, vitality of new cells maintained, new bone formation occurred. When compared to control group, radiological healing was statistically significantly better in omentum and omentum with PRP-treated groups $(p=0.047)$. Furthermore histological healing was better in the omentum and omentum with PRP-treated groups than both control and omentum with mesenchymal stem cell-treated groups according to Salkeld Scoring System $(p=0.001)$.

Conclusion: The use of decellularized omentum scaffold is suitable in the healing of critical bone defects.

\section{Introduction:}

The frequency of bone defect problems encountering by orthopaedic surgeons are increasing. High energy trauma, open fractures, bone tumors, infections, debridement of bone for any reason, metabolic diseases and massive osteolysis are the most common causes of bone defects [1]. Main problems in dealing with bone defects are high cost and long time needed for healing. Critical bone defect is more difficult situation and termed for defects when self-healing is not expected despite enough surgical stabilization [2]. In addition to appropriate surgical stabilization, critical bone defect treatment must include proper and functional segmental replacement regardless of the cause. In the literature, autologous bone grafts (ABG) are described as the gold standard among current treatment modalities [3]. However, due to some disadvantages such as limited availability and donor site morbidity, the efforts to find more appropriate and optimal scaffold options continue.

The bone scaffold is a 3D matrix that allows osteogenic cell adhesion, proliferation, and also stimulates cells [4]. Natural and synthetic polymers, ceramic-based scaffolds, metallic, and composite scaffolds have been tried so far but none of the used scaffolds contain all the properties of an optimal scaffold [5, 6]. Also, synthetic scaffolds are associated with rejection, allergic reactions and failure to integrate with host tissues. As a result, tissue engineering in current technological upgrades is seminal in bone defect treatment. Presently, natural extracellular matrix composite scaffolds are of interest because these are 
accepted as most similar to the original tissue and allow cellular adhesion and proliferation, also the main advantage of this scaffold type is being non-antigenic to the native tissue [7]. The omentum has been used for defects of other organs because of its rich extracellular matrix, ability to adhere to local tissues and growth factors containment but it is generally used in reconstructive and cardiovascular surgery as a decellularized omentum scaffold. However, in orthopedic surgery, decellularized omentum scaffolds have not been used to date [8].

Successful bone repair is based on combination of a suitable medium, stem cells and growth factors. Platelet-rich plasma (PRP), which has osteoinductive and osteoconductive properties is a good candidate to be added on a scaffold [9]. It is proven to have a number of growth and differentiation factors that play important roles in the intracellular signaling pathway for cellular proliferation, osteoid and extracellular matrix formation, and also callus formation in fracture healing [10]. Also, mesenchymal stem cells (MSCs) were shown to be involved in callus formation [11]. Both direct involvements in callus formation and inflammatory cytokines such as transforming growth factor (TGF)- $B$, insulin-like growth factor (IGF), and epidermal growth factor (EGF) production is stimulated by MSCs [12].

Therefore, we aimed to evaluate the effects of an decellularized omentum scaffold in critical bone defects. Also, the potential osteoinductive effects of the combination of PRP and MSCs were also investigated.

\section{Methods:}

The study was executed after receiving approval of the local ethics committee from Hacettepe University Medical Faculty Animal Research Laboratory, (Date: 25.07.2017, 2017/49 - 08)

\subsection{Mesenchymal Stem Cell Isolation and In-vitro Expansion}

Firstly, the permission was obtained from the local ethics committee (2016/03 - 01) for the use of mononuclear cells which were taken from 8 years old female bone marrow donors, isolated in our archive cryostocks and stored at $-196^{\circ} \mathrm{C}$ until use. $20 \times 10^{6}$ isolated cells planted into the tissue culture medium in T-75 flasks with $10 \mathrm{ml}$ of growth medium, $10 \%$ fetal bovine serum (DMEM-LG) with $1 \%$ penicillinstreptomycin antibiotics. Incubation was performed at $37^{\circ} \mathrm{C}$ in $5 \% \mathrm{CO}_{2}$. When cells reached $70-80 \%$ confluence at 7-12 days, medium were irrigated with a $0.25 \%$ trypsin/EDTA solution for mobilization of non-adherent cells. Then adhesive cells were cultured in T-75 flask with of a density $2 \times 10^{3} \mathrm{cells} / \mathrm{cm}^{2}$. In subsequent passages, cells were checked every day with an inverted microscope for non-adherent cells and the medium changed every three days to remove non-adherent cells. At 4th passage, adherent cells showed fibroblastic morphology and a homogenous cell population was obtained in all cultures. The cells demonstrated $95 \%$ positivity for stromal markers including CD29, CD44, CD73, CD90 and CD105 (eBiosciences, USA). Hematopoietic markers, CD146, CD45 and CD34 (e-Biosciences, USA), were negative. The differentiation capacity of MSCs was confirmed by positive staining in osteogenic and adipogenic 
differentiation assays after 21 days of culture. A $1 \times 10^{6}$ cell count for every rat in fetal bovine solution with $0.5 \mathrm{ml}$ volume was prepared [13].

\subsection{Decellularized Omentum Scaffold Preparation}

For the preparation of the decellularized omentum, the omentum obtained from patients who had an abdominal surgery for non-tumorous surgeries were used after receiving ethics committee approval $(2017 / 49-08)$. Omentum tissue was kept at $-80^{\circ} \mathrm{C}$, and dissolved gradually to $+4^{\circ} \mathrm{C}$. First, tissues were washed with PBS solution for 24 hours in a 1 liter flask. After washing, tissues placed for intermittent shaking in a shaker for 24 hours to be smashed, then smashed tissues placed in $1 \%(\mathrm{w} / \mathrm{v})$ sodium dodecyl sulfate solution and shaken at a constant shaking rate, also for 24 hours. The smashed pieces were washed out with PBS solution three times to remove the excess SDS remaining in the tissues. Tissues in PBS were replaced in separate tubes for 48 hours in isopropanol solution (\%99.9) to remove the lipid tissues. The last part was the enzymatic release of the RNA and DNA, with RNase and DNase (Sigma-Aldrich) in $37^{\circ} \mathrm{C}$ incubation for 16 hours. The remaining decellularized omentum parts were washed out with PBS solution and placed into Petri dishes in a sterile conditions ready for use in surgical procedures [14].

\subsection{PRP Preparation}

Two rats were sacrificed through intracardiac blood aspiration, after an intraperitoneal injection of 50 $\mathrm{mg} / \mathrm{kg}$ ketamine hydrochloride anesthesia. A sterile disposable monovette, containing $3.2 \%$ sodium citrate system, was centrifuged at 1800 rcf for 10 minutes. After the first centrifugation, two layers were seen in the monovette; the yellow layer consisted of PRP and the red layer of erythrocytes and leucocytes. After separating the two layers, the yellow layer was centrifuged at $4000 \mathrm{rcf}$ for 10 minutes. The upper portion of the layer was platelet-poor plasma and a lower layer of $1 \mathrm{~cm}$ was PRP. The separated part of the lower layer was collected and transferred into an injector for use 30 minutes before starting the surgical procedure.

\subsection{Animal preparation and surgical procedure:}

Thirty male, inbred Wistar-Albino rats weighing over $300 \mathrm{~g}$ were included in the study after acclimating the laboratory environment for 10 days. The rats had not been involved in any previous experiments and were also screened for any diseases. They were kept in metal cages with access to water and food ad libidum. The rats were maintained in $22^{\circ} \mathrm{C} \pm 2^{\circ} \mathrm{C}$ environmental conditions with 12 hours of light and 12 hours of darkness. The animals were fasted for 24 hours before the procedure.

Five groups were made randomly:

1. Control group $(n=6)$

2. Scaffold group $(n=6)$

3. Scaffold + PRP group $(n=6)$ 


\section{Scaffold + Mesenchymal stem cell group $(n=6)$ \\ 5. Scaffold + PRP + Mesenchymal stem cell group $(n=6)$}

Before surgical procedure, decellularized omentum cut into $0.5 \mathrm{~cm}^{3}$ pieces and saturated with $0.5 \mathrm{ml}$ PRP or $0.5 \mathrm{ml} \mathrm{MSC}$ or both PRP and MSC, outside the surgery site in a Petri dish and waited 5 minutes to adhere on scaffold. All rats were anesthetized with $50 \mathrm{mg} / \mathrm{kg}$ dose of intraperitoneal ketamine hydrochloride injection. All rats were monitored by a veterinarian during the surgery. The surgical position of rats was supine and both forelimbs were shaved. $0.5 \mathrm{~cm}^{3}$ sized bone defects were created in all rats' in both radius bones with a $5 \mathrm{~mm}$ Kerrison reungeur. Periosteal elevation and muscle retraction were not performed in any rats. The bone defect site was treated according to the following group protocol: group 1 , bone defect left empty; group 2, previously prepared decellularized omentum sized $0.5 \mathrm{~cm}^{3}$ was placed to all rats' forelimbs; group 3, previously prepared decellularized omentum sized $0.5 \mathrm{~cm}^{3}$, saturated with $0.5 \mathrm{ml} \mathrm{PRP}$; group 4, previously prepared decellularized omentum sized $0.5 \mathrm{~cm}^{3}$, saturated with $0.5 \mathrm{ml}$ MSCs; and group 5, previously prepared decellularized omentum sized $0.5 \mathrm{~cm}^{3}$, saturated with both PRP and MSCs $0.5 \mathrm{ml}$. (Fig. 1) No fixation method was used for the bone. Wound was closed with nonabsorbable sutures. After the surgical procedure, while rats were under anesthesia, $15 \mathrm{mg} / \mathrm{kg}$ tramadol was used for postoperative analgesia. Each group of rats was labeled and caged in a separate cage with no restriction of activities.

\subsection{Radiologic Analysis}

After waiting for 6 weeks of healing, the rats were euthanized and the forelimbs were disarticulated from the glenohumoral joint in order to obtain anterior-posterior X-rays. Two orthopedic surgeons who were blinded to the groups but was informed about the evaluation method performed in the radiologic assessment. Results were scored using the grading scale described by Cook et al. (Table 1) [15].

\subsection{Histopathologic Analysis}

After disarticulation of the forelimbs, the specimens were fixed in a $10 \%$ formaldehyde solution for 2 weeks. Then, samples were placed in $10 \%$ ethylenediaminetetraacetic acid solution for the decalcification process. Samples were embedded in paraffin blocks and 5 - $\mu \mathrm{m}$-thick sections were cut through the long axis from the bone defect zone and stained with hematoxylin and eosin (H\&E) stain for light microscope analysis. The best sections of the specimens were evaluated by two histolopathologists in Histology and Embryology Department, which were informed about the histologic grading scale described by Salkeld et al. (Table 2) [16].

\subsection{Statistical Analysis}

The SPSS software, version of 21.0 was used for statistical analysis. Descriptive statistics included median (minimum and maximum) values. Kruskal-Wallis analysis of variance (ANOVA) was used to compare the groups in terms of histologic, radiologic, and biomechanical results. After performing Kruskal-Wallis ANOVA, the Mann-Whitney $U$ test was performed with Bonferroni correction for paired 
comparison of groups. Results are expressed with $95 \%$ confidence intervals. Significance was defined as $\mathrm{p}<0.05$.

\section{Results:}

All 30 rats woke from anesthesia and no major wounds or other complications occurred. All rats were euthanized and radiologic and histopathologic studies were performed.

\subsection{Radiologic Findings}

A total of 60 sample assessments were performed according to the Cook scale. In the radiologic assessment, compared to control group, radiological healing was significantly higher in omentum and omentum with PRP-treated groups $(p=0.047$ and $p=0.047)$. Also, the omentum and omentum and PRP groups had significantly higher healing than the omentum and mesenchymal stem cell group $(p=0.047$ and $p=0.047$ ) (Table 3). Radiologic data are shown in Fig. 2.

\subsection{Histopathological Findings}

Histologically, in the sections, the defect was still visible when looking at the control sample, and there were new bone islands and adipose tissue near the defective areas. In the omentum group specimen, the defect was completely loaded with new cells and the scaffold was organized. In the omentum and mesenchymal stem cell group specimen, the scaffold was still visible, meaning collagen was visible, most of the living cells and newly formed fat cells were in the scaffold with some bone islands and minimal calcification. In the omentum and PRP specimen, a reduction of defect size and increased calcification was observed with a fully organized scaffold with bone cells. In the omentum and mesenchymal stem cell and PRP group, there were increased vascular structures and fat tissue as well as increased bone islands and calcification compared to omentum and mesenchymal stem cell group sample. Histologic sections are shown in Fig. 3.

Forty samples were assessed according to the method of Salkeld et al. Evaluation was based on the following parameters: (1) quality of union, (2) cortical development and remodeling, and (3) new bone formation.

Between the five groups, there was a significant difference according to the Salkeld scoring system, for each parameter and total score. For the quality of the union, the control group was significantly lower than omentum and omentum + PRP used groups $(p=0.004$ and $p=0.016)$. Also, the omentum + mesenchymal stem cell-treated group was significantly lower than omentum and omentum + PRP-treated groups $(p=0.001$ and $p=0.006)$.

According to the cortical development and remodeling scores, the control group was significantly lower than the omentum and omentum + PRP-treated groups $(p=0.001$ and $p=0.001)$. Also, the omentum + mesenchymal stem cell-treated group was significantly lower than the omentum and omentum + PRPtreated groups $(p=0.001$ and $p=0.007)$. 
According to the new bone formation scores, the control group was significantly lower than the omentum and omentum + PRP-treated groups $(p=0.001$ and $p=0.001)$. Also, the omentum + mesenchymal stem cell-treated group was significantly lower than the omentum and omentum + PRP-treated groups $(p=$ 0.013 and $p=0.016)$.

For total scores, the control group was significantly lower than the omentum and omentum + PRP-treated groups $(p=0.001$ and $p=0.001)$. Also, the omentum + mesenchymal stem cell-treated group was significantly lower than the omentum and omentum + PRP-treated groups $(p=0.002$ and $p=0.003)$ (Table 4) (Fig. 4).

After use of our decellularized omentum scaffold, the vitality of new cells was maintained, new bone formation occurred, the defect size became smaller and vanished, and also the scaffold was resorbed. With the combination of MSCs, new bone formation was diminished and bone healing was damaged. Decellularized omentum with a combination of PRP increased bone healing.

\section{Discussion:}

The present study is an experimental animal study, which evaluates whether the decellularized omentum could be used as effective scaffold in ciritcal bone defect. In the previous literature it was well shown that decellularized scaffolds promote cellular adhesion and migration in addition to cell proliferation and differentiation [17]. We preferred omentum in our study because of its natural basis to increase the biocompatibility. For current literature, many studies showed that omentum provided support and growth of the cells as a bioreactor in soft tissues $[18,19]$. However decellularized omentum has never been tried in orthopedic literature as a scaffold, our study for the first time showed that decellularized omentum could be used as an efficient scaffold. We investigate omentum in animal model despite its human origin but it should be kept in mind that decellularization process provides us to lose the antigenic activity of the omentum.

Histologic data showed that ossification was seen, the defect shrank, and resorption of the scaffold accrued. Also, groups in which the scaffold was used, it was seen that the decellularized omentum scaffold allowed cellular adhesion and proliferation and supported cellular vitality. This results made us think that the omentum is an inspiring scaffold that can be used in the treatment of critical bone defects.

The other goal of the study was to find a way to increase bone healing in addition to suitable scaffold. PRP were proven to increase bone healing in the literature previously [20]. In our study, histologically, PRP combination with omentum had higher organized ossification and bone mineralization than the omentum only group. Also, the PRP + mesenchymal stem cell and omentum combination group had higher bone islands than the mesenchymal stem cell and omentum combination group. These results shows that PRP increases bone union microscopically.

For bone healing, the two methods, MSCs and PRP, were demonstrated to achieve improvement. Even though we prepared allogenic PRP, we could not prepare allogenic MSCs due to technical drawbacks. 
However, previous animal studies that used human-origin MSCs with or without a suitable scaffold illustrated no systemic or local rejection reactions, which encouraged us to design our study [21, 22].

There are various studies regarding the effects of MSC usage in the healing of critical bone defects. In some studies, it was shown that MSC combinations increase osteoinduction and osteogenesis [23, 24]. CD44, CD45, CD73, CD90, and CD105 surface markers are essential for using of MSC in the orthopedic treatments to achieve osteogenic formation [25]. In our study, we used MSCs that express those surface markers. Although the decellularized omentum scaffold allowed cell adhesion and proliferation and the used MSCs had potential for osteogenic transformation, microscopic examinations and Salkeld scoring systems showed decreased bone healing and new bone formation.

There are studies claiming direct injection of MSCs into critical bone defect and non-unions impairs healing. When we looked at the mechanism which may have caused this, it was shown that bolus MSC could lead to reduction in gene expression of Runt-related transcription factor-2 (Runx2) and Osterix pathway via TNF-a which was responsible for the transformation of MSCs to osteogenic cells [26]. It is known that cumulative MSC expression causes an decreasement in TNF-a [27, 28]. Scaffold application with low doses of TNF-a decreased osteogenic activation and high doses of TNF-a increased osteogenic activation in an experimental rat study [29]. The anti-inflammatory effect of cumulative MSC application might have decreased TNF-a levels in our scaffold and callus formation. This knowledge led us to speculate that this may be the reason for impairment of osteogenic formation with MSC application.

Using xenogenic mesenchymal stem cells could be another reason for decreased healing. Although there are many studies that used xenogenic mesenchymal stem cells that caused no local or systemic rejections, but also some contraversial studies that describing human mesenchymal stem cell apoptosis and fragmentation in immune-competent mice [30]. It has been reported that xenogeneic, MSC-derived chondrocytes trigger $\mathrm{T}$ lymphocyte proliferation, cytotoxicity, increasing antigen presentation and further activation of the adaptive immune response [31]. Possibility of localized immune reaction and diminishing mesenchymal stem cells may also explain impairment of osteogenic formation [32].

Radiologic results showed a correlation to our histologic results. We think that these correlation empower our study. However, our scaffold was not fully ossified and radiologic healing was not seen completely. There is no similar study in the literature to discuss how much time would be needed for radiological healing.

One of the limitations of our study is the limited number of samples. Another limitation is that although PRP is allogenic, MSCs are not. Due to technical drawbacks, rat-origin MSCs could not be used in our study. In addition, we did not investigate the important features of our scaffold such as porosity, and micro, and nano construct.

\section{Conclusion:}


This research demonstrates that a decellularized omentum scaffold is suitable for critical-sized bone defects, and similar results in in-vivo tests and biomechanical studies highlights to usage of decellularized omentum being used as a scaffold in clinical practice for segmental bone defects.

\section{Abbreviations:}

ABG: Autologous Bone Grafts

PRP: Platelet Rich Plasma

MSC: Mesenchymal Stem Cell

\section{Declarations:}

Funding: This research did not receive any specific grant from funding agencies in the public, commercial, or not-for-profit sectors.

Authors' Contributions: AE made the animal preperation and surgical procedure, also analyzed and interpreted the data. EO and ET performed the measurements and scorings of radiologic data. ACSY and $\mathrm{RH}$ performed the histologic data analysis. DUC and EK prepared the mesenchymal stem cells. AE and ET reviewed the manuscript and plan the research. All authors read and approved the final manuscript.

Availability of Data and Materials: The data used and/or analysed during the current study are available from the corresponding author on reasonable request

Consent for Publication: Not applicable

Competing Interest: Authors have no competing interest to declare.

Acknowledgments: The authors thank to Tissue Laboratory for decellularized omentum production and also Stem Cell Laboratory workers for their high efforts.

Ethics Approval: Hacettepe University Medical Faculty Animal Research Laboratory, (Date: 25.07.2017, 2017/49-08)

\section{References:}

1. Nauth, A., et al., Managing bone defects. Journal of orthopaedic trauma, 2011. 25(8): p. 462-466.

2. Keating, J., A. Simpson, and C. Robinson, The management of fractures with bone loss. The Journal of bone and joint surgery. British volume, 2005. 87(2): p. 142-150.

3. Parikh, S.N., Bone graft substitutes in modern orthopedics. Orthopedics, 2002. 25(11): p. 1301-1309.

4. Ghassemi, T., et al., Current concepts in scaffolding for bone tissue engineering. Archives of bone and joint surgery, 2018. 6(2): p. 90. 
5. Polo-Corrales, L., M. Latorre-Esteves, and J.E. Ramirez-Vick, Scaffold design for bone regeneration. Journal of nanoscience and nanotechnology, 2014. 14(1): p. 15-56.

6. Yoon, D.M. and J.P. Fisher, Natural and synthetic polymeric scaffolds, in Biomedical Materials. 2009, Springer. p. 415-442.

7. Moradi, A., et al., Chondrogenic potential of physically treated bovine cartilage matrix derived porous scaffolds on human dermal fibroblast cells. Journal of biomedical materials research Part A, 2016. 104(1): p. 245-256.

8. Porzionato, A., et al., Decellularized omentum as novel biologic scaffold for reconstructive surgery and regenerative medicine. European journal of histochemistry: EJH, 2013. 57(1).

9. Parizi, A.M., et al., Human platelet rich plasma plus Persian Gulf coral effects on experimental bone healing in rabbit model: radiological, histological, macroscopical and biomechanical evaluation. Journal of Materials Science: Materials in Medicine, 2012. 23(2): p. 473-483.

10. Marx, R.E., et al., Platelet-rich plasma: growth factor enhancement for bone grafts. Oral Surgery, Oral Medicine, Oral Pathology, Oral Radiology, and Endodontology, 1998. 85(6): p. 638-646.

11. Xing, Z., et al., Rejuvenation of the inflammatory system stimulates fracture repair in aged mice. Journal of Orthopaedic Research, 2010. 28(8): p. 1000-1006.

12. Caplan, A.I. and D. Correa, The MSC: an injury drugstore. Cell stem cell, 2011. 9(1): p. 11-15.

13. Uckan, D., et al., Adipocyte differentiation defect in mesenchymal stromal cells of patients with malignant infantile osteopetrosis. Cytotherapy, 2009. 11(4): p. 392-402.

14. Soffer-Tsur, N., et al., Optimizing the biofabrication process of omentum-based scaffolds for engineering autologous tissues. Biofabrication, 2014. 6(3): p. 035023.

15. Cook, S.D., et al., Recombinant human bone morphogenetic protein-7 induces healing in a canine long-bone segmental defect model. Clinical Orthopaedics and Related Research ${ }^{\circledR}, 1994$. 301: p. 302312.

16. Salkeld, S.L., et al., The effect of osteogenic protein-1 on the healing of segmental bone defects treated with autograft or allograft bone. JBJS, 2001. 83(6): p. 803-816.

17. Yow, K.H., et al., Tissue engineering of vascular conduits. British journal of surgery, 2006. 93(6): p. 652-661.

18. Masuda, T., M. Furue, and T. Matsuda, Novel strategy for soft tissue augmentation based on transplantation of fragmented omentum and preadipocytes. Tissue engineering, 2004. 10(11-12): p. 1672-1683.

19. Baumert, H., et al., Development of a seeded scaffold in the great omentum: feasibility of an in vivo bioreactor for bladder tissue engineering. european urology, 2007. 52(3): p. 884-892.

20. Turhan, E., et al., A comparison of the effects of platelet-rich plasma and demineralized bone matrix on critical bone defects: An experimental study on rats. 2017.

21. Niemeyer, P., et al., Xenogenic transplantation of human mesenchymal stem cells in a critical size defect of the sheep tibia for bone regeneration. Tissue Engineering Part A, 2010. 16(1): p. 33-43. 
22. Kim, J., et al., Bone regeneration using hyaluronic acid-based hydrogel with bone morphogenic protein-2 and human mesenchymal stem cells. Biomaterials, 2007. 28(10): p. 1830-1837.

23. Fricain, J.C., et al., A nano-hydroxyapatite-pullulan/dextran polysaccharide composite macroporous material for bone tissue engineering. Biomaterials, 2013. 34(12): p. 2947-2959.

24. Campos, D.F.D., et al., Three-dimensional printing of stem cell-laden hydrogels submerged in a hydrophobic high-density fluid. Biofabrication, 2012. 5(1): p. 015003.

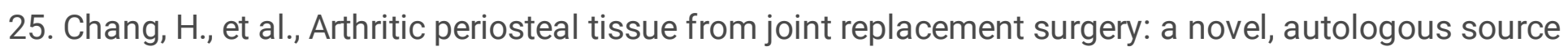
of stem cells. Stem cells translational medicine, 2014. 3(3): p. 308-317.

26. Kawane, T., et al., Runx2 is required for the proliferation of osteoblast progenitors and induces proliferation by regulating Fgfr2 and Fgfr3. Scientific reports, 2018. 8(1): p. 1-17.

27. Cho, H.H., et al., NF-KB activation stimulates osteogenic differentiation of mesenchymal stem cells derived from human adipose tissue by increasing TAZ expression. Journal of cellular physiology, 2010. 223(1): p. 168-177.

28. Lu, Z., et al., Short-term exposure to tumor necrosis factor-alpha enables human osteoblasts to direct adipose tissue-derived mesenchymal stem cells into osteogenic differentiation. Stem cells and development, 2012. 21(13): p. 2420-2429.

29. Mountziaris, P.M., S.N. Tzouanas, and A.G. Mikos, Dose effect of tumor necrosis factor-a on in vitro osteogenic differentiation of mesenchymal stem cells on biodegradable polymeric microfiber scaffolds. Biomaterials, 2010. 31(7): p. 1666-1675.

30. Leibacher, J., et al., Human mesenchymal stromal cells undergo apoptosis and fragmentation after intravenous application in immune-competent mice. Cytotherapy, 2017. 19(1): p. 61-74.

31. Chen, X., et al., Chondrogenic differentiation alters the immunosuppressive property of bone marrowderived mesenchymal stem cells, and the effect is partially due to the upregulated expression of B7 molecules. Stem Cells, 2007. 25(2): p. 364-370.

32. Longoni, A., et al., Endochondral Bone Regeneration by Non-autologous Mesenchymal Stem Cells. Frontiers in bioengineering and biotechnology, 2020. 8: p. 651.

\section{Tables:}


Table 1

Radiographic grading scale for degree of healing (Cook et al.)

\begin{tabular}{|lc|}
\hline Description & Score \\
\hline No change from immediate postoperative appearance & 0 \\
\hline A slight increase in radiodensity distinguishable from the graft & 1 \\
\hline $\begin{array}{l}\text { Recognizable increase in radiodensity, bridging of one cortex with new bone formation from } \\
\text { the graft }\end{array}$ & 2 \\
\hline $\begin{array}{l}\text { Bridging of at least one cortex with material of non uniform radiodensity, early incorporation } \\
\text { of th graft suggested by obscurity of graft borders }\end{array}$ & 3 \\
\hline $\begin{array}{l}\text { Defect bridged on both medial and lateral sides with bone of uniform radiodensity, cut ends } \\
\text { of the cortex still visible, graft and new bone not easy to differentiate }\end{array}$ & 4 \\
\hline $\begin{array}{l}\text { Same as grade 3, with at least one of four cotices obscured by new bone } \\
\text { Defect bridged by uniform new bone, cut ends of cortex no longer distinguishable, graft no }\end{array}$ & 6 \\
\hline longer visible
\end{tabular}


Table 2

Histological grading scale for the degree of healing (Salkeld et al.)

\begin{tabular}{|c|c|c|}
\hline Criteria & Description & Score \\
\hline \multirow[t]{5}{*}{ Quality of union } & No sign of fibrous or other union & 0 \\
\hline & Fibrous union & 1 \\
\hline & Fibrocartilagenous union or cartilage union & 2 \\
\hline & Mineralizing cartilage and bone union & 3 \\
\hline & Bone union & 4 \\
\hline \multirow{5}{*}{$\begin{array}{l}\text { Cortex development } \\
\text { and remodelling }\end{array}$} & No cortex formed & 0 \\
\hline & Formation of new bone along exterior borders & 1 \\
\hline & $\begin{array}{l}\text { Recognizable formation of both the outer cortex border and the } \\
\text { medullary space }\end{array}$ & 2 \\
\hline & Coritces formed but incomplete bridging & 3 \\
\hline & Complete formation of cortices with bridging of defect & 4 \\
\hline \multicolumn{3}{|l|}{$\begin{array}{l}\text { Bone-graft } \\
\text { incorporation and new } \\
\text { bone formation }\end{array}$} \\
\hline \multirow{3}{*}{$\begin{array}{l}\text { No new bone, al lor } \\
\text { most of graft visible }\end{array}$} & Graft material present, no incorporation, no new bone formation & 0 \\
\hline & $\begin{array}{l}\text { Graft present, some incorporation with new bone formation and } \\
\text { small amount of new bone }\end{array}$ & 1 \\
\hline & $\begin{array}{l}\text { Graft present, some incorporation with new bone formation and } \\
\text { moderate amount of new bone }\end{array}$ & 2 \\
\hline \multirow[t]{3}{*}{$\begin{array}{l}\text { Decreasing graft, } \\
\text { increasing new bone }\end{array}$} & $\begin{array}{l}\text { Graft present, some incorporation with new bone formation } \\
\text { continuous with host bone and early remodelling changes in new } \\
\text { bone }\end{array}$ & 3 \\
\hline & $\begin{array}{l}\text { Decresed amount of graft (compared with grade } 3 \text { ) good } \\
\text { incorporation of graft and new bone with host and ample new } \\
\text { bone }\end{array}$ & 4 \\
\hline & $\begin{array}{l}\text { Less amount of graft still visible (compared with grade 4), good } \\
\text { incorporation of graft and new bone with host and ample new } \\
\text { bone }\end{array}$ & 5 \\
\hline $\begin{array}{l}\text { No graft visible, } \\
\text { extensive new bone }\end{array}$ & $\begin{array}{l}\text { Difficult to differantiate graft from new bone, excellent } \\
\text { incorporation and advanced remodelling of new bone with graft } \\
\text { and host }\end{array}$ & 6 \\
\hline
\end{tabular}


Table 3

Radiological assessment scoring of groups accoding to Cook criteria

\begin{tabular}{|lccccc|}
\hline Group & N & Median & Minimum & Maximum & P \\
\hline Control & 12 & 1.0 & 0 & 1 & \\
\hline Omentum & 12 & 1.5 & 1 & 3 & \\
\hline Omentum + Mesenchymal stem cell & 12 & 1.0 & 0 & 1 \\
\hline Omentum + PRP & 12 & 1.5 & 1 & 3 \\
\hline Omentum + Mesenchymal stem cell + PRP & 12 & 1.0 & 0 & 3 \\
\hline
\end{tabular}

* Data are given according to median (minimum-maximum)

Table 4

Histopathological assessment scoring of groups according to Salkeld et al.

\begin{tabular}{|c|c|c|c|c|}
\hline & $\begin{array}{l}\text { Quality } \\
\text { of union }\end{array}$ & $\begin{array}{l}\text { Cortical Development } \\
\text { and Remodelling }\end{array}$ & $\begin{array}{l}\text { New Bone } \\
\text { Formation }\end{array}$ & $\begin{array}{l}\text { Total } \\
\text { Score }\end{array}$ \\
\hline Control & $\begin{array}{l}2 \\
(1-2)\end{array}$ & $\begin{array}{l}0 \\
(0-0)\end{array}$ & $\begin{array}{l}1 \\
(0-1)\end{array}$ & $\begin{array}{l}3 \\
(1-3)\end{array}$ \\
\hline Omentum & $\begin{array}{l}3 \\
(2-3)\end{array}$ & $\begin{array}{l}3 \\
(2-3)\end{array}$ & $\begin{array}{l}3 \\
(3-3)\end{array}$ & $\begin{array}{l}9 \\
(7-9)\end{array}$ \\
\hline $\begin{array}{l}\text { Omentum + Mesenchymal } \\
\text { stem cell }\end{array}$ & $\begin{array}{l}1.5 \\
(1-2)\end{array}$ & $\begin{array}{l}0 \\
(0-1)\end{array}$ & $\begin{array}{l}1 \\
(1-2)\end{array}$ & $\begin{array}{l}2.5 \\
(2-5)\end{array}$ \\
\hline Omentum + PRP & $\begin{array}{l}3 \\
(2-3)\end{array}$ & $\begin{array}{l}2.5 \\
(2-3)\end{array}$ & $\begin{array}{l}3.5 \\
(2-4)\end{array}$ & $\begin{array}{l}8.5 \\
(6- \\
10)\end{array}$ \\
\hline $\begin{array}{l}\text { Omentum + Mesenchymal } \\
\text { stem cell + PRP }\end{array}$ & $\begin{array}{l}2 \\
(2-3)\end{array}$ & $\begin{array}{l}2 \\
(0-3)\end{array}$ & $\begin{array}{l}2 \\
(1-3)\end{array}$ & $\begin{array}{l}6.5 \\
(3-9)\end{array}$ \\
\hline
\end{tabular}

* Data are given according to median (minimum-maximum)

\section{Figures}

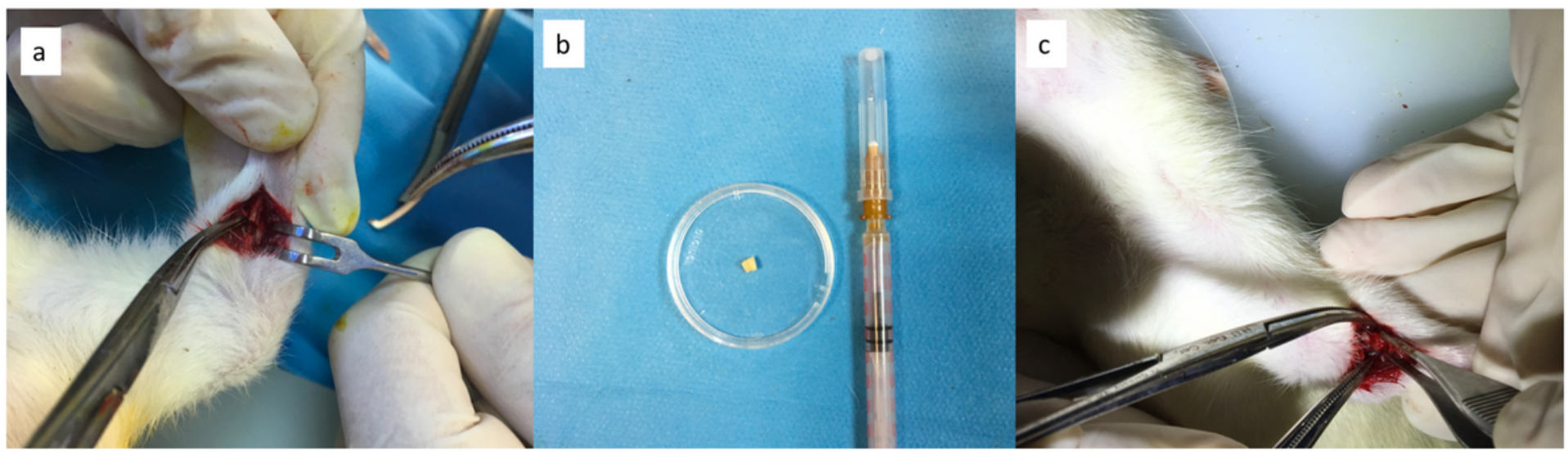




\section{Figure 1}

Surgical procedure. a) Bone defect b) Decellularized omentum scaffold with mesenchymal stem cells c) Bone defect treated with scaffold

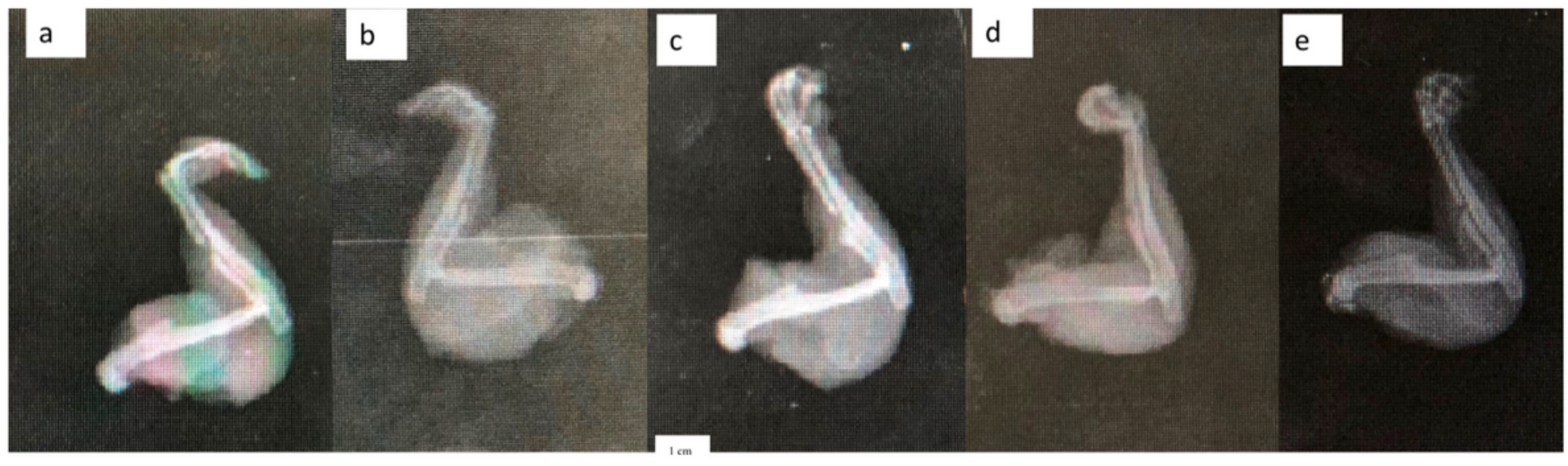

Figure 2

Radiologic samples of the groups. a) Control group b) Omentum group c) Omentum and Mesenchymal stem cell group d) Omentum and PRP group e) Omentum and Mesenchymal stem cell and PRP group 


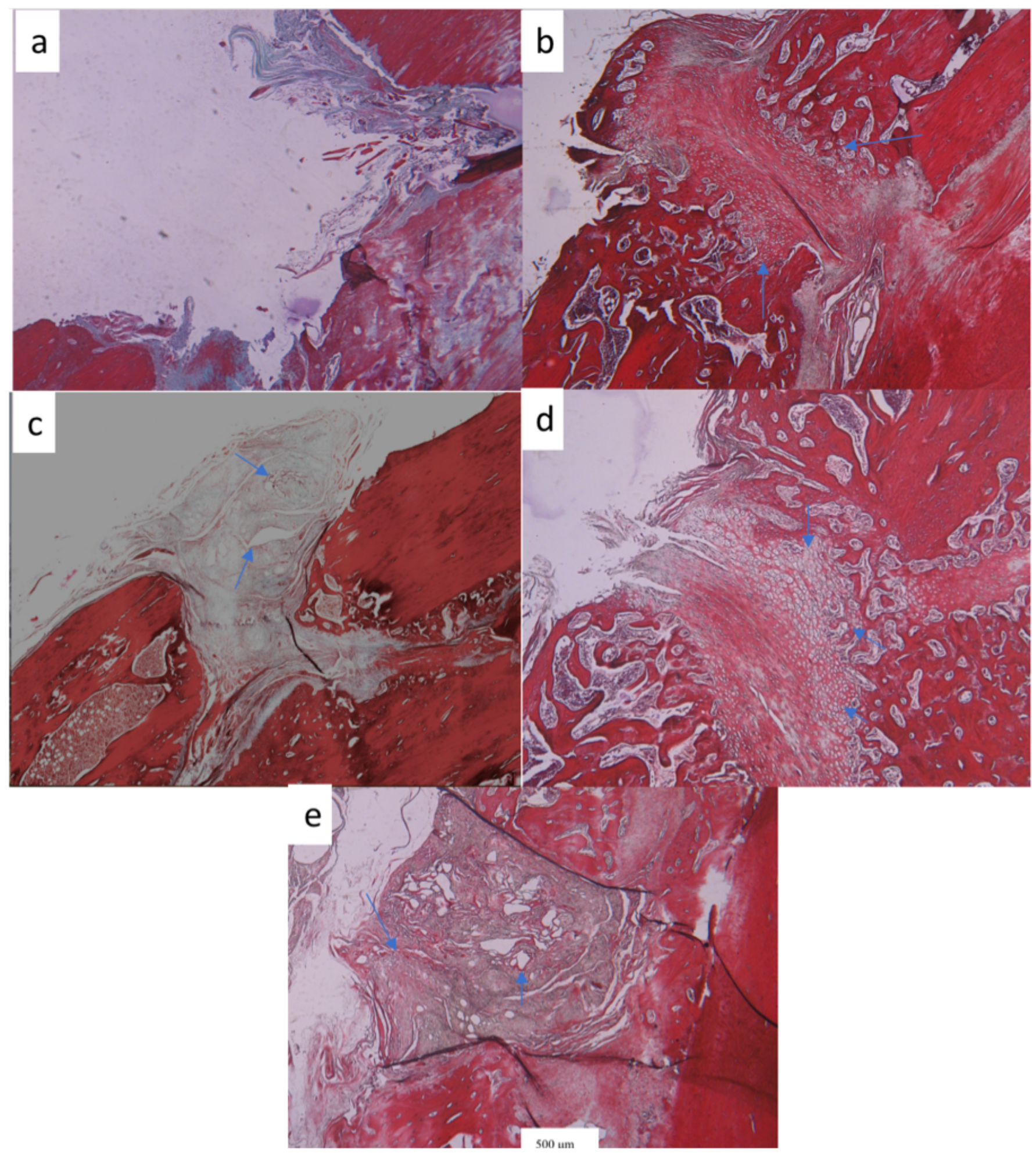

\section{Figure 3}

Histopathologic sample of each group. (a) control group sample $4 x$ magnification, defect still seen with new bone islands and fat tissue. (b) omentum group sample $4 x$ magnification, defect fully loaded with new cells and scaffold was organized (c) omentum and mesenchymal stem cell sample $4 x$ magnification, scaffold still seen with blue color with new formed fat cells within scaffold and minimal calcification d) omentum and PRP group sample 4x magnification, with shrinkage of defect size with full 
organized scaffold, with bone islands e) omentum and mesenchymal stem cell and PRP group 4x magnification, increased vascular structures and fat tissue, also increased bone islands and calcification 10

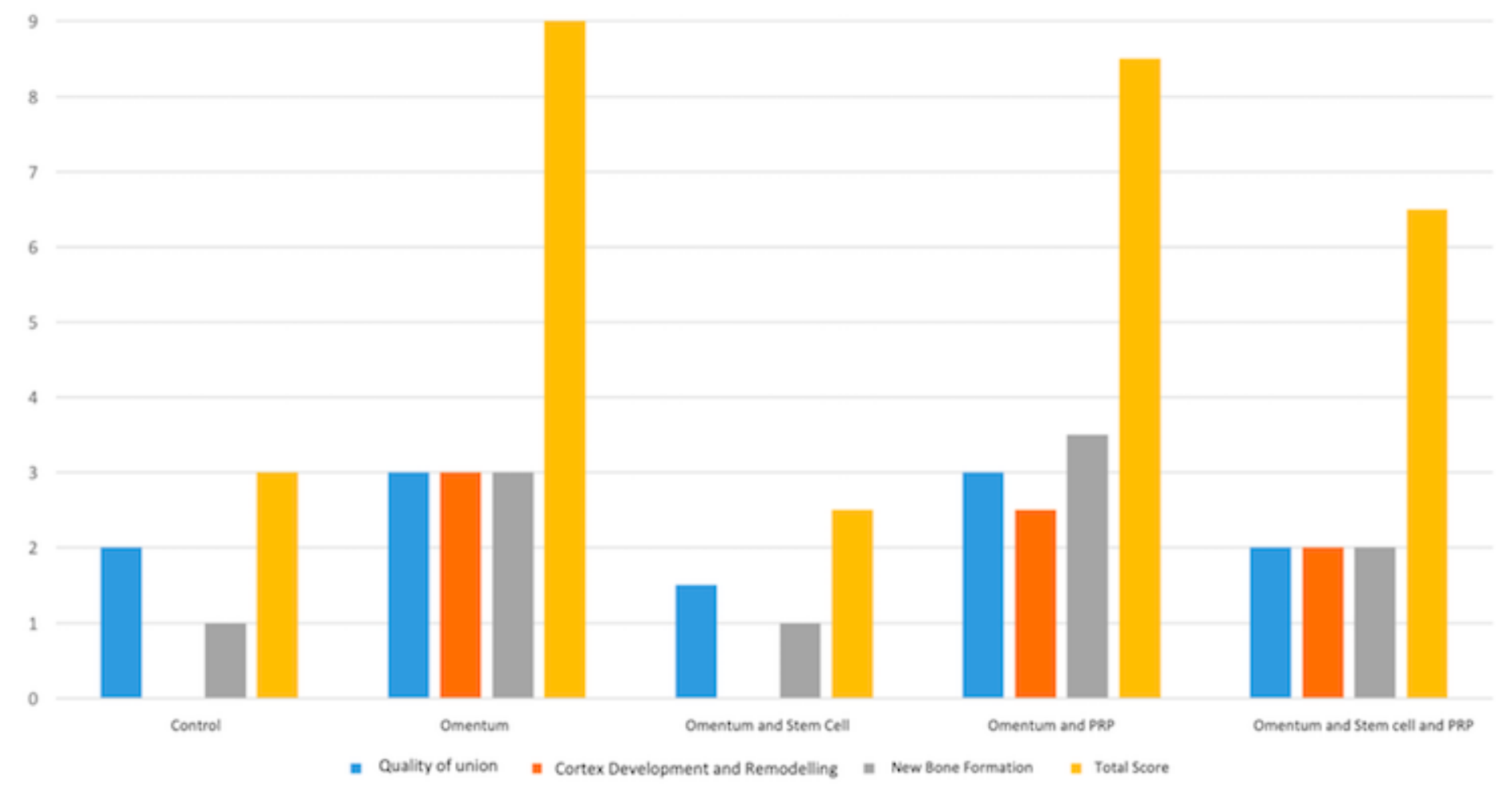

Figure 4

Graphic of Salkeld scoring system 